\title{
Performance Measurement of the Unicorns Based on Balanced Scorecard
}

\author{
Yuan $\mathrm{Gao}^{1, \mathrm{a}}$, Yougan Zhu ${ }^{2, \mathrm{~b},{ }^{*}}$ and Chengzhi Niu ${ }^{3, \mathrm{c}}$ \\ ${ }^{1}$ College of Business, Beijing Institute of Fashion Technology, Chaoyang District, Beijing, China \\ ${ }^{2}$ Accounting Teaching and Research Office, Beijing Institute of Fashion Technology, Chaoyang \\ District, Beijing, China \\ ${ }^{3}$ College of Business, Beijing Institute of Fashion Technology, Chaoyang District, Beijing, China \\ Agaoyuan2567@163.com, bzyg2368@sina.com, 'cmacrov@yeah.net \\ *Yougan Zhu
}

Keywords: Unicorn enterprise, Performance measurement, Balanced scorecard, Analytic hierarchy process.

\begin{abstract}
In recent years, the unicorn enterprises have attracted extensive attention in the capital market. As far as the performance measurement of such enterprise is concerned, the performance indicators of traditional balanced scorecard performance measurement methods are not fully applicable anymore. This article takes this as the starting point, combines the characteristics of the unicorns, and gives a new content to the four dimensions of the balanced scorecard, to construct the unicorn enterprises' performance measurement system based on the balanced scorecard perspective.
\end{abstract}

\section{The raise of the question}

Aileen Lee, the American venture capitalist and founder of Cowboy Ventures, proposed the concept of "unicorn" in 2013. Since then, the unicorns have gradually been recognized and become a new topic of the capital market. Although the performance of the unicorns is not prominent, the valuation has reached to more than one billion US dollars now and keep growing in high-speed, which can bring new impetus to the industry and the entire economy. Compared to the traditional performance measurement indicators such as return on investment, residual income, economic added value, and market added value, the balanced scorecard can balance the financial and non-financial indicators and evaluate the performance from the four dimensions of finance, customer, internal operation, learning and growth. However, due to the special characteristics of the unicorns, the relevant indicators of the four dimensions of the traditional balanced scorecard are not fully applicable to the unicorn enterprise. This article takes this as an entry point and combines the characteristics of the unicorns to give a new connotation to the four dimensions of the balanced scorecard, thus constructing a unicorn performance measurement index system based on the balanced scorecard perspective.

\section{The performance measurement method of the unicorns based on balanced scorecard}

With the development of China's economy and the corporate innovation capabilities, the number of the unicorns in China has exploded since 2013. Up to April 2019, there were 202 unicorn enterprises in China with a total valuation of over 5 trillion yuan. In this context, the construction of the performance measurement method based on the balanced scorecard combines the characteristics of the unicorns and give the balanced scorecard four new dimensions.

\subsection{Characteristics of the unicorn enterprises}

Compared with other companies, the unicorns have the following characteristics:

2.1.1 They are concentrated in first-tier and second-tier cities, especially in the city with rapid development of science and technology

According to the "2018 Hurun Greater China Unicorn Index" published by Hurun Research Institute, among the 202 unicorn enterprises in China, most of the unicorn enterprises establish in Beijing, 
Shanghai, Hangzhou and Shenzhen, occupying more than $80 \%$ share of the unicorns in China. It shows that the unicorns are mostly concentrated in the first-tier and second-tier cities with rapid development of science and technology, thus the regional characteristic of the unicorns is obvious.

\subsubsection{They are technology-driven and industry-oriented companies}

From the perspective of the industry, the unicorns are concentrated in industries such as artificial intelligence, big data, cloud computing, new energy, and new retail. In 2019, the number of unicorn enterprises in the Internet service, e-commerce, Internet finance, medical health, culture and entertainment industries occupied $70 \%$ of the total number of Chinese unicorn enterprises, and this proportion will continue to increase. These industries are highly technologically advanced and technology-driven has become an important feature of the unicorns in these industries.

\subsubsection{Intangible assets account for a large proportion}

It can be observed from the characteristics of the industry that the unicorns are mainly distributed in the fields of Internet, e-commerce and technology-driven industries. These types of enterprises have a relatively obvious feature: intangible assets account for a large proportion of total assets. Intangible assets are highly profitable, and the unicorns can increase their core competitiveness by increasing the proportion of intangible assets in the asset structure to achieve rapidly growth.

\subsubsection{Even if the financial performance is not outstanding, the valuation of the unicorns keeps a high} level

Although the financial performance of Chinese unicorns in the list is not outstanding, the top ten unicorn companies in China are valued at more than 10 billion US dollars. Among them, the number one company Ant Financial is valued at about 100 billion yuan. In essence, the financing environment and growth potential are the two major simulations of corporate valuation. Chinese policies support high-tech development, thus created a superior financing environment for unicorn enterprises. At the same time, the unicorns have always been highly focused in the field of Internet, high-tech and medical services in capital market. The financing environment and growth potential have led to the high valuation of the Chinese unicorn companies.

\subsection{Construction of a performance measurement method for the unicorns based on the Balanced Scorecard}

When constructing a unicorn enterprise performance measurement method based on the Balanced Scorecard, it must be considered that the financial performance of such enterprises is not outstanding, while the characteristics of high valuation, rapid development, technology-driven, and technological innovation ability are very strong, which derive from the short-term performance optimization, long-term performance growth, the increase of enterprise value, the improvement of team innovation ability, and the enhancement of research and development capabilities. Therefore, this paper advocates giving the balanced scorecard a new connotation of the four dimensions of finance, customer, internal operation, learning and growth, so as to achieve a comprehensive measurement of the performance of the unicorn enterprise.

\subsubsection{Optimization of financial data}

Financial performance indicators can intuitively reflect business results over a period of time and guide companies to make correct strategic decisions. The financial dimension indicators of the traditional balanced scorecard usually include profit, income, cash flow, return on investment, and economic value added. Considering the characteristics of the unicorns, the profitability can be evaluated by the return on net assets, and the operational capability can be evaluated by the intangible asset turnover rate in terms of the optimization of the financial data. At the same time, when selecting the financial dimension indicators, the five sets of market capitalization and financial indicator standards for the initial public offering and listing on the Science and Technology Board can also be considered, which are the estimated market value, operating income, net profit, R\&D investment and net cash flow. Taking the above factors into account, this paper selects four indicators in the financial dimension: operating income growth rate, intangible asset turnover rate, net profit rate, and estimated market value. 


\subsubsection{Optimization of customer perspectives}

Common customer dimension indicators of traditional balanced scorecards include on-time delivery rate, new product sales as a percentage of total sales, important customer purchase share, customer satisfaction index, customer loyalty, new customer increase ratio, customer profit contribution, etc. As far as the optimization of the customer dimension is concerned, the unicorn enterprise should design the customer dimension index of the balanced scorecard to finally reflect the value of the stakeholders in the value chain. In the customer dimension, the design of the unicorn enterprise balanced scorecard can provide services that exceed customers' expectation by providing customer brand awareness, value-added distribution and supply chain service, and implementing integrated communication channels. Taking the above factors into account, this paper selects four indicators in the customer dimension: customer satisfaction, brand awareness improvement, customer retention rate, new customer acquisition rate.

\subsubsection{Optimization of internal business processes}

As a driver element of the financial dimension and the customer dimension, the performance appraisal of internal business processes should focus on achieving financial goals and customer satisfaction. Traditional balanced scorecard indicators of the internal business process dimension include production layout and competition, production cycle, unit cost, output ratio, defect rate, inventory ratio, new product input plan and actual investment, design efficiency, raw material finishing time, production preparation time, order delivery accuracy, payment recovery and management, after-sales guarantee, etc. In terms of internal business process dimension optimization, the unicorn enterprise balanced scorecard can be designed around the enhancement of various products and services, the minimization of product cycle time, the establishement of simple, consistent and reliable processes, the implement of a first-class corporate governance model and so on. At the same time, we must pay attention to the quality of products and after-sales service, so as to improve customer satisfaction and achieve operating income. Taking the above factors into account, this paper selects four indicators in the internal business process dimension: R\&D expense rate, product production cycle, product return/rework rate, and after-sales service response cycle.

\subsubsection{Optimization of learning and growth}

In the learning and growth dimension, the design of the balanced scorecard should mainly focus on hiring, nurturing and retaining the best performing employees, as well as using technology to improve productivity, achieving customer effects, and creating a culture that encourages teamwork and promotes equality. The traditional balanced scorecard can ensure different product innovation, process innovation and production level improvement indicators based on the difference between the operating environment and profit growth points. The learning and growth dimension is at the bottom of the balanced scorecard strategy map, but it is the basic part of the entire strategic map, since human capital is the most important source of value for any organization. Taking the above factors into account, this paper selects four indicators in the learning and growth dimension: employee training expense rate, key employee retention rate, adoption of employee recommendations, and employee productivity.

\section{Calculation of index weights based on the Analytic Hierarchy Process}

The Analytic Hierarchy Process (AHP) is a hierarchical weighting decision method proposed by Professor Satie of the University of Pittsburgh in the early 1970s. The analytic hierarchy process builds a decision-making system based on a target problem, and further decomposes multiple criteria under one target into several indicators, and then quantifies the weights through the judgment matrix to provide a basis for decision-making. The specific analysis steps of the AHP are as follows:

\subsection{Establishing a hierarchical structure model}

According to the selection results of the unicorn enterprise performance measurement indicators of the four dimensions of the above balanced scorecard, a structural model can be constructed among three layers: the target layer, the criterion layer and the indicator layer. The target layer is the main research object of this paper__ performance measurement of the unicorns based on balanced 
scorecard; the criterion layer is the four dimensions of the balanced scorecard - finance, customer, internal business process, learning and growth; the indicator layer expresses 16 indicators selected from these four dimensions. The hierarchical model of the construction is shown in Table 1.

Table 1 Unicorn Enterprise Performance measurement Index System

\begin{tabular}{|c|c|c|}
\hline Target layer & Criterion layer & Indicator layer \\
\hline \multirow{16}{*}{$\begin{array}{c}\text { Performance } \\
\text { measurement of the } \\
\text { unicorns based on } \\
\text { balanced scorecard } \\
\text { A }\end{array}$} & \multirow{4}{*}{ Financial data $B_{1}$} & Operating income growth rate $\mathrm{C}_{1}$ \\
\hline & & Intangible asset turnover $\mathrm{C}_{2}$ \\
\hline & & Net profit rate $C_{3}$ \\
\hline & & Estimated market value $\mathrm{C}_{4}$ \\
\hline & \multirow{4}{*}{$\begin{array}{c}\text { Customer } \\
\text { perspectives } B_{2}\end{array}$} & customer satisfaction $\mathrm{C}_{5}$ \\
\hline & & Brand Awareness $\mathrm{C}_{6}$ \\
\hline & & Customer retention rate $\mathrm{C}_{7}$ \\
\hline & & New customer acquisition rate $C_{8}$ \\
\hline & \multirow{4}{*}{$\begin{array}{l}\text { Internal business } \\
\text { process } B_{3}\end{array}$} & R\&D expense ratio $C_{9}$ \\
\hline & & Product production cycle $\mathrm{C}_{10}$ \\
\hline & & Product return / rework rate $\mathrm{C}_{11}$ \\
\hline & & After-sales service reaction cycle $\mathrm{C}_{12}$ \\
\hline & \multirow{4}{*}{$\begin{array}{l}\text { Learning and growth } \\
\qquad \mathrm{B}_{4}\end{array}$} & Staff training expense rate $\mathrm{C}_{13}$ \\
\hline & & Key employee retention rate $C_{14}$ \\
\hline & & Employee recommendation adoption $\mathrm{C}_{15}$ \\
\hline & & Employee productivity $\mathrm{C}_{16}$ \\
\hline
\end{tabular}

\subsection{Constructing a judgment matrix}

This paper utilizes the Delphi method (expert investigation method) to construct the judgment matrix. Firstly, an A-B judgment matrix is constructed between the target layer and the criterion layer, and then four B-C judgment matrices are constructed between the criterion layer and the index layer. In order to minimize the influence of subjectivity and one-sidedness on the research results, this paper invites university professors and enterprise experts to jointly judge and rate the importance of the indicators, and then transforms the scored result into a judgment matrix with analytic hierarchy scale method (Table 2). After words, the median is taken in the judgment matrix from each expert, and each one of the four dimensions will respectively acquire a unique judgment matrix.

Table 2 AHP Scale Table

\begin{tabular}{|c|c|}
\hline Scale & Meaning \\
\hline 1 & Two elements have the same importance \\
\hline 3 & The former element is slightly more important than the latter \\
\hline 5 & The former element is obviously more important than the latter \\
\hline 7 & The former element is significantly more important than the latter \\
\hline 9 & The former element is exceedingly more important than the latter \\
\hline $2 、 6 、 8$ & Indicates the intermediate value of the above adjacent judgment \\
\hline Reciprocal & Indicates the exchange of order of two elements \\
\hline
\end{tabular}

First, the A-B judgment matrix is constructed between the target layer and the criterion layer (Table 3). 
Table 3 A-B Judgment Matrix

\begin{tabular}{|c|c|c|c|c|}
\hline $\mathrm{A}$ & $\mathrm{B}_{1}$ & $\mathrm{~B}_{2}$ & $\mathrm{~B}_{3}$ & $\mathrm{~B}_{4}$ \\
\hline $\mathrm{B}_{1}$ & 1 & 2 & 3 & 3 \\
\hline $\mathrm{B}_{2}$ & $1 / 2$ & 1 & 2 & 2 \\
\hline $\mathrm{B}_{3}$ & $1 / 3$ & $1 / 2$ & 1 & 1 \\
\hline $\mathrm{B}_{4}$ & $1 / 3$ & $1 / 2$ & 1 & 1 \\
\hline
\end{tabular}

Then, four B-C judgment matrixes are constructed between the criterion layer and the indicator layer(Table 4-7).

Table $4 \mathrm{~B}_{1}$-C Judgment Matrix (Financial Dimensions)

\begin{tabular}{|c|c|c|c|c|}
\hline $\mathrm{B}_{1}$ & $\mathrm{C}_{1}$ & $\mathrm{C}_{2}$ & $\mathrm{C}_{3}$ & $\mathrm{C}_{4}$ \\
\hline $\mathrm{C}_{1}$ & 1 & 2 & 3 & 3 \\
\hline $\mathrm{C}_{2}$ & $1 / 2$ & 1 & 2 & 2 \\
\hline $\mathrm{C}_{3}$ & $1 / 3$ & $1 / 2$ & 1 & 1 \\
\hline $\mathrm{C}_{4}$ & $1 / 3$ & $1 / 2$ & 1 & 1 \\
\hline
\end{tabular}

Table $5 \mathrm{~B}_{2}-\mathrm{C}$ Judgment Matrix (Customer Dimension)

\begin{tabular}{|c|c|c|c|c|}
\hline $\mathrm{B}_{2}$ & $\mathrm{C}_{5}$ & $\mathrm{C}_{6}$ & $\mathrm{C}_{7}$ & $\mathrm{C}_{8}$ \\
\hline $\mathrm{C}_{5}$ & 1 & 3 & 7 & 5 \\
\hline $\mathrm{C}_{6}$ & $1 / 3$ & 1 & 5 & 3 \\
\hline $\mathrm{C}_{7}$ & $1 / 7$ & $1 / 5$ & 1 & $1 / 3$ \\
\hline $\mathrm{C}_{8}$ & $1 / 5$ & $1 / 3$ & 3 & 1 \\
\hline
\end{tabular}

Table $6 \mathrm{~B}_{3}$-C Judgment Matrix (Internal Process Dimension)

\begin{tabular}{|c|c|c|c|c|}
\hline $\mathrm{B}_{3}$ & $\mathrm{C}_{9}$ & $\mathrm{C}_{10}$ & $\mathrm{C}_{11}$ & $\mathrm{C}_{12}$ \\
\hline $\mathrm{C}_{9}$ & 1 & 7 & 5 & 7 \\
\hline $\mathrm{C}_{10}$ & $1 / 7$ & 1 & $1 / 3$ & 1 \\
\hline $\mathrm{C}_{11}$ & $1 / 5$ & 3 & 1 & 3 \\
\hline $\mathrm{C}_{12}$ & $1 / 7$ & 1 & $1 / 3$ & 1 \\
\hline
\end{tabular}

Table 7 B 4 -C Judgment Matrix (Learning and Growth Dimension)

\begin{tabular}{|c|c|c|c|c|}
\hline $\mathrm{B}_{4}$ & $\mathrm{C}_{13}$ & $\mathrm{C}_{14}$ & $\mathrm{C}_{15}$ & $\mathrm{C}_{16}$ \\
\hline $\mathrm{C}_{13}$ & 1 & 1 & 3 & 5 \\
\hline $\mathrm{C}_{14}$ & 1 & 1 & 3 & 5 \\
\hline $\mathrm{C}_{15}$ & $1 / 3$ & $1 / 3$ & 1 & 3 \\
\hline $\mathrm{C}_{16}$ & $1 / 5$ & $1 / 5$ & $1 / 3$ & 1 \\
\hline
\end{tabular}




\subsection{Calculating weights and conducting consistency tests}

The detailed steps of using AHP to calculate the weight and perform the consistency test are as follows: firstly, the normalization process is performed according to the judgment matrix, and then the matrix is added by the summation method to obtain a feature vector X (Eq.1), the feature vector is further normalized to obtain a weight vector W. Then, the weight vector W (Eq.2) is multiplied by the matrix to obtain the weight AW (Eq.3) of the judgment matrix. Afterwards, the maximum eigenvalue $\lambda \max ($ Eq.4) and the consistency index CI (Eq.5) can be calculated in sequence. When the CI is closer to 0 , the consistency of the matrix is stronger, and the larger the CI is, the more serious the inconsistency will be. Then another consistency indicator RI is introduced to measure the size of the CI. The value of RI can be searched from the Table 8. Finally, the test coefficient CR (Eq.6) can be easily calculated. In general, if $\mathrm{CR}<0.1$, the matrix passes the consistency check, otherwise the judgment matrix must be reconstructed until the consistency check is passed.

$$
\begin{gathered}
\mathrm{X}=\left(\mathrm{X}_{1}, \mathrm{X}_{2}, \ldots, \mathrm{X}_{\mathrm{n}}\right)^{\mathrm{T}} . \\
\mathrm{W}=\left(\mathrm{W}_{1}, \mathrm{~W}_{2}, \ldots, \mathrm{W}_{\mathrm{n}}\right)^{\mathrm{T}} . \\
\mathrm{AW}=\left(\mathrm{AW}_{1}, \mathrm{AW}_{2}, \ldots, \mathrm{AW}_{\mathrm{n}}\right)^{\mathrm{T}} . \\
\lambda \max =\frac{1}{n} \sum_{i=1}^{n} \frac{(\mathrm{AW}) i}{\mathrm{~W} i} . \\
C I=\frac{\lambda \max -n}{n-1} . \\
C R=\frac{C I}{R I} .
\end{gathered}
$$

Table 8 Standard values of the consistency indicator RI

\begin{tabular}{|c|c|c|c|c|c|c|c|c|c|c|}
\hline Matrix order & 1 & 2 & 3 & 4 & 5 & 6 & 7 & 8 & 9 & 10 \\
\hline RI & 0 & 0 & 0.58 & 0.90 & 1.12 & 1.24 & 1.32 & 1.41 & 1.45 & 1.49 \\
\hline
\end{tabular}

According to the A-B judgment matrix, the maximum eigenvalue $\lambda \max =4.0109, \mathrm{CI}=0.0036$, $\mathrm{RI}=0.9$, test coefficient is $\mathrm{CR}=\mathrm{CI} / \mathrm{RI}=0.004, \mathrm{CR}<0.1$ shows that the result passes the consistency test, and the weight of four-dimensional matrix is $(0.4547,0.2631,0.1411,0.1411)^{\mathrm{T}}$.

\begin{tabular}{|c|c|c|}
\hline $\begin{array}{c}\text { Criterion Layer and } \\
\text { Weight }\end{array}$ & Indicator Layer and Weight & $\begin{array}{l}\text { Relative } \\
\text { Weight }\end{array}$ \\
\hline \multirow{4}{*}{ Financial Data $45.47 \%$} & Operating income growth rate $45.47 \%$ & $20.67 \%$ \\
\hline & Intangible assets turnover rate $26.31 \%$ & $11.96 \%$ \\
\hline & Net profit margin $14.11 \%$ & $6.42 \%$ \\
\hline & Estimated market value $14.11 \%$ & $6.42 \%$ \\
\hline \multirow{4}{*}{$\begin{array}{c}\text { Customer Perspectives } \\
26.31 \%\end{array}$} & Customer satisfaction $55.78 \%$ & $14.67 \%$ \\
\hline & Brand awareness $26.34 \%$ & $6.93 \%$ \\
\hline & Customer retention rate $12.19 \%$ & $3.21 \%$ \\
\hline & New customer acquisition rate $5.69 \%$ & $1.50 \%$ \\
\hline \multirow{2}{*}{$\begin{array}{l}\text { Internal Business } \\
\text { Processes } 14.11 \%\end{array}$} & R\&D expense ratio $64.74 \%$ & $9.13 \%$ \\
\hline & Product production cycle $7.82 \%$ & $1.10 \%$ \\
\hline
\end{tabular}

The maximum eigenvalues $\lambda$ max obtained in the judgment matrix of finance, customer, internal process, learning and growth are 4.0109, 4.1186, 4.0753, 4.0441, and the test coefficients CR are $0.004,0.0439,0.0279,0.0163$. The four CR are less than 0.1 , so the judgment matrix passes the consistency test, and the weight of the indicator layer is shown in Table 9.

Table 9 Unicorn Enterprise Performance measurement Index Weight Table 


\begin{tabular}{|c|c|c|}
\cline { 2 - 3 } & Product return / rework rate $19.62 \%$ & $2.77 \%$ \\
\cline { 2 - 3 } Learning and Growth & After-sales service reaction cycle $7.82 \%$ & $1.10 \%$ \\
\hline \multirow{3}{*}{$14.11 \%$} & Staff training expense rate $38.89 \%$ & $5.49 \%$ \\
\cline { 2 - 3 } & Key employee retention rate $38.89 \%$ & $5.49 \%$ \\
\cline { 2 - 3 } & $\begin{array}{c}\text { Employee recommendation adoption level } \\
15.35 \%\end{array}$ & $2.17 \%$ \\
\cline { 2 - 3 } & Employee productivity $6.87 \%$ & $0.97 \%$ \\
\hline
\end{tabular}

\section{Research conclusions and recommendations}

Through the construction of the unicorn enterprise balance scorecard system, the unique performance measurement index system is obtained. When evaluating the performance of the unicorn enterprise, we should pay special attention to the measurement of the index with higher weight. From the financial perspectives, due to the country's policy direction and the arrival of the Science and Technology Board, the measurement index of operating income growth rate is particularly important. The growth rate of operating income is an important indicator for evaluating the growth and development capabilities of a company, and can be used to measure the business status and market possession of a company. For unicorn enterprises, the intangible assets turnover rate can clearly show the effectiveness of intangible assets, and the faster the intangible assets turnover rate is, the stronger the efficiency ot intangible assets will be. The market value and net profit margin will also be appreciated in order to meet the application conditions of the Science and Technology Board. In view of the importance of the financial data among the four dimensions, market value and net profit margin occupy a relatively high weight in the vertical view of the balanced scorecard. Because "brand effect" is based on high-speed development of the high-tech era of capital, the unicorns should pay more attention to customer satisfaction and brand awareness in terms of customer dimension. Customer retention is relatively important than new customer acquisition rates, because the cost of maintaining an old customer is much lower than the cost of developing a new customer, and old customers often bring potential new customers. In the internal business processes dimension, the $R \& D$ expense ratio of the unicorns is much more important than others since it can enable the unicorns to master the most advanced science and technology. The five sets of market capitalization and financial indicators of the Science and Technology Board also have requirements for accumulating R\&D investment, because high-tech enterprises have to invest a lot of resources for R\&D. The learning and growth dimension is as important as the internal process dimension. The employee training expense rate and the key employee retention rate are the focus of the unicorn enterprise in this dimension. In the era of talent and technology, it can enable employees to create more value for the company while pays more attention to the cultivation of talents and increase the talents.

When the unicorns use the Balanced Scorecard to build a performance measurement system, they should pay attention to their own characteristics and the trend of the times. The four dimensions of the Balanced Scorecard are full of flexibility and can be adjusted according to the current development of the company. According to the characteristics of the unicorn enterprise, this paper gives the four dimensions of the balanced scorecard a new connotation. The unicorn enterprise can replace the less important measurement indexes with more important indexes when constructing the performance measurement system.

\section{Acknowledgment}

This research was financially supported by the Supporting Funds for the Discipline Construction Project of the Graduate School of Beijing Institute of Fashion Technology (Grand NO.

120301990125/006). 


\section{References}

[1] R. S. Kaplan and D. P. Norton, Strategy Maps: Converting Intangible Assets into Tangible Outcomes, New York: Harvard Business Press, 2003.

[2] Xin Liu, The League of Chinese "Unicorns", China Today, vol.67, pp.45-47, 2018.

[3] Jing Chen and Jianguo $\mathrm{Xu}$, The Rise of the Unicorns: Typical Facts and Driven Factors, Shanghai Finance, vol.49, pp. 12-20, 2019.

[4] Junyong Liu and Yan Meng, The Serviceability of the Balanced Scorecard: a experimental research, Accounting Research, vol.95, pp. 36-42, 2011.

[5] Yunkun Zhang, Analysis of Enterprise Performance measurement System Based on Balanced Scorecard: Taking GEM Listed Companies as an Example, Communication of Finance and Accounting, vol.18, pp. 64-65, 2013.

[6] Yan Yang, Determination of the Weight of Performance Management Index Based on Balanced Scorecard: An Empirical Study of Analytic Hierarchy Process, Commercial modernization, vol.10, pp. 116-117, 2008. 